\title{
Modifikasi Varian Metode Abbasbandy dengan Orde Konvergensi Tujuh Tanpa Turunan Kedua
}

\author{
Tuti Adawiyah $^{1 *}$, Muhammad Nizam Muhaijir $^{2}$ \\ 1,2 Jurusan Matematika, Fakultas Sains dan Teknologi, UIN Sultan Syarif Kasim Riau, \\ Jl. HR. Soebrantas Panam Km. 15 No. 155, Kota Pekanbaru 28293, Riau, Indonesia \\ *Penulis Korespondensi. Email: tutiadawiyah27@gmail.com
}

\begin{abstract}
ABSTRAK
Varian metode Abbasbandy tanpa turunan kedua merupakan salah satu metode iterasi yang memiliki orde konvergensi empat yang digunakan untuk menyelesaikan persamaan nonlinear. Penelitian ini memodifikasi varian Abbasbandy menjadi metode iterasi tiga langkah. Turunan yang terdapat pada metode iterasi tersebut diaproksimasi menggunakan interpolasi polinomial, interpolasi Hermit orde dua dan interpolasi Lagrange orde tiga. Secara analitik, metode baru ini mempunyai konvergensi orde tujuh dengan melibatkan empat evaluasi fungsi sehingga indeks efisiensi $7^{1 / 4} \approx$ 1,6265. Simulasi numerik dilakukan menggunakan beberapa fungsi untuk membandingkan metode ini dengan beberapa metode lain seperti metode Newton, metode Abbasbandy, metode Halley, metode Arif-Muhaijir, dan metode Wartono-Rosela untuk menunjukkan performa metode iterasi yang ditemukan.
\end{abstract}

Kata Kunci:

Metode Newton; Metode Abbasbandy; Metode Halley; Interpolasi

\section{ABSTRACT}

The variant of the Abbasbandy method without the second derivative is an iterative method that has a four-convergence order used to solve nonlinear equations. This research, modified the Abbasbandy variant one-step method being threestep method. The derivatives in the iteration method are approximated using polynomial interpolation, second order Hermit interpolation and third order Lagrange interpolation. Analytically, this new method has 7 th order convergence involving four evaluation functions so that the efficiency index is $7^{1 / 4} \approx 1,6265$. Numerical simulations are carried out using several functions to compare this method with several other methods such as Newton method, Abbasbandy method, Halley method, Arif-Muhaijir method and Wartono-Rosela method, to use the analysis method found.

\section{Keyzords:}

Newton Method; Abbasbandy Method; Halley Method; Interpolation

Format Sitasi:

T. Adawiyah and M. N. Muhaijir, "Modifikasi Varian Metode Abbasbandy dengan Orde Konvergensi Tujuh Tanpa Turunan Kedua," Jambura J. Math., vol. 2, no. 1, pp.39-48, 2020 


\section{T. Adawiyah, et.al}

\section{Pendahuluan}

Di bidang matematika sering ditemui persoalan bagaimana menemukan solusi suatu persamaan nonlinear dalam bentuk

$$
f(x)=0 .
$$

Permasalahan yang sering muncul ketika menyelesaikan Persamaan (1) adalah tidak dapat digunakan metode analitik dalam menyelesaikannya. Alternatif lain untuk menyelesaikan Persamaan (1) adalah menggunakan metode numerik dengan hitungan komputasi yang bersifat perulangan atau yang sering dikenal dengan metode iterasi.

Banyak metode iterasi yang dapat digunakan, salah satunya yaitu metode Newton dengan menggunakan satu tebakan awal dalam menemukan akar hampiran dari Persamaan (1). Bentuk iterasinya dinyatakan dalam bentuk

$$
x_{n+1}=x_{n}-\frac{f\left(x_{n}\right)}{f^{\prime}\left(x_{n}\right)}, n=1,2,3, \ldots, \operatorname{dan} f^{\prime}\left(x_{n}\right) \neq 0 .
$$

Metode Newton memiliki orde konvergensi kuadratik [1] dengan dua evaluasi fungsi. Metode ini telah dikembangkan dan dibahas dalam beberapa penelitian seperti pada [2] yang memiliki orde konvergensi tujuh, lima dan empat dan [3] yang memiliki orde konvergensi tujuh.

Metode iterasi lain yang sering digunakan untuk menyelesaikan Persamaan (1) adalah metode Halley yang memiliki orde konvergensi kubik [4][5] dengan bentuk iterasi yaitu

$$
x_{n+1}=x_{n}-\frac{2 f\left(x_{n}\right) f^{\prime}\left(x_{n}\right)}{2 f^{\prime}\left(x_{n}\right)^{2}-f\left(x_{n}\right) f^{\prime \prime}\left(x_{n}\right)}, n=1,2,3, \ldots
$$

Abbasbandy mengerjakan metode iterasi yang diperoleh dari pengembangan metode dekomposisi Adomian dengan bentuk iterasi,

$$
x_{n+1}=x_{n}-\frac{f\left(x_{n}\right)}{f^{\prime}\left(x_{n}\right)}-\frac{\left(f\left(x_{n}\right)\right)^{2} f^{\prime \prime}\left(x_{n}\right)}{2\left(f^{\prime}\left(x_{n}\right)\right)^{3}}-\frac{\left(f\left(x_{n}\right)\right)^{3}\left(f^{\prime \prime}\left(x_{n}\right)\right)^{2}}{2\left(f^{\prime}\left(x_{n}\right)\right)^{5}}
$$

dengan orde konvergensi tiga [6]. Muhaijir dan Aljarizi mengembangkan metode Abbasbandy tanpa turunan kedua dengan orde konvergensi empat [7], dengan bentuk iterasi,

$$
x_{n+1}=y_{n}-\left(1+\frac{2 f\left(y_{n}\right)}{f\left(x_{n}\right)}\right) \frac{f\left(y_{n}\right)}{f^{\prime}\left(x_{n}\right)}, n=1,2,3, \ldots
$$

Penelitian ini mengembangkan metode iterasi tiga langkah dengan mengombinasikan Persamaan (2) sebagai langkah pertama, Persamaan (5) sebagai langkah kedua, dan Persamaan (3) sebagai langkah ketiga. Selanjutnya, orde konvergensi metode iterasi yang diperoleh ditunjukkan secara analitik menggunakan deret Taylor. Terakhir, uji komputasi dilakukan pada metode iterasi baru untuk melihat orde konvergensi secara numerik serta untuk melihat keunggulan metode dengan beberapa metode yang digunakan sebagai pembanding. 


\section{Metode}

Metode yang digunakan dalam penelitian ini merupakan studi literatur dengan langkah-langkah sebagai berikut:

1. Mendefinisikan kembali metode pada Persamaan (2) sebagai langkah pertama, Persamaan (5) sebagai langkah kedua, dan Persamaan (3) sebagai langkah ketiga dengan mengganti $x_{n}$ menjadi $z_{n}$.

2. Selanjutnya, Persamaan (3) didefiniskan kembali dengan mengganti $f^{\prime \prime}\left(z_{n}\right)$ menjadi $f^{\prime \prime}\left(y_{n}\right)$ seperti yang dilakukan oleh Syakir dkk. [8].

3. Fungsi $f^{\prime \prime}\left(y_{n}\right)$ ditaksir seperti yang dilakukan oleh Noor dkk. [9] karena taksiran $f^{\prime \prime}\left(y_{n}\right)$ masih memuat $f^{\prime}\left(y_{n}\right)$ untuk mengurangi fungsi maka dilakukan lagi penyetaraan seperti yang dilakukan oleh Muhaijir dan Aljarizi [7]. Kemudian, fungsi $f^{\prime}\left(z_{n}\right)$ pada langkah ketiga ditaksir menggunakan metode penyetaraan seperti yang dilakukan oleh Wartono dan Rasela [2] sehingga diperoleh metode iterasi baru tiga langkah tanpa turunan kedua.

4. Menentukan orde konvergensi dan indeks efisiensi untuk metode iterasi yang diperoleh serta melakukan simulasi numerik menggunakan program Maple 13.

Selanjutnya disajikan beberapa definisi dasar untuk pembahasan dan proses terbentuknya metode iterasi baru.

Definisi 1 (Orde Konvergensi) [10] Sebuah barisan iterasi $\left\{x_{n} \mid n \geq 0\right\}$ dikatakan konvergen dengan orde $p \geq 1$ ke $f^{\prime \prime}\left(y_{n}\right)$ jika

$$
\left|\alpha-x_{n+1}\right| \leq c\left|\alpha-x_{n}\right|^{p}, n \geq 0,
$$

untuk suatu konstanta $c>0$. Jika $p=1$, maka barisan disebut konvergen linear ke $\alpha$.

Definisi 2 (COC) [11][12] Misalkan $\alpha$ adalah akar persamaan nonlinear $f\left(x_{n}\right)$ dan andaikan $x_{n-1}, x_{n}$, dan $x_{n+1}$ adalah tiga iterasi berturut-turut yang cukup dekat ke akar $\alpha$. Maka computational order of convergence (COC) dapat diaproksimasi menggunakan rumus:

$$
\operatorname{COC} \approx \frac{\ln \left|\left(x_{n+1}-\alpha\right) /\left(x_{n}-\alpha\right)\right|}{\ln \left|\left(x_{n}-\alpha\right) /\left(x_{n-1}-\alpha\right)\right|}
$$

Definisi 3 (Indeks Efisiensi) [13] Misalkan $q$ adalah banyak evaluasi fungsi yang dibutuhkan oleh suatu metode iterasi. Efisiensi dari metode tersebut dihitung dengan indeks efisiensi yang didefinisikan sebagai $p^{1 / q}$, dengan $p$ adalah orde konvergensi dari metode tersebut.

\section{Hasil dan Pembahasan}

Pada bagian ini, metode iterasi tiga langkah pada Persamaan (2), (3), dan (5) dikembangkan sebagai berikut: 


$$
\begin{aligned}
y_{n} & =x_{n}-\frac{f\left(x_{n}\right)}{f^{\prime}\left(x_{n}\right)}, \\
z_{n} & =y_{n}-\left(1+\frac{2 f\left(y_{n}\right)}{f\left(x_{n}\right)}\right) \frac{f\left(y_{n}\right)}{f^{\prime}\left(x_{n}\right)}, \\
x_{n+1} & =z_{n}-\frac{2 f\left(z_{n}\right) f^{\prime}\left(z_{n}\right)}{2 f^{\prime}\left(z_{n}\right)^{2}-f\left(z_{n}\right) f^{\prime \prime}\left(z_{n}\right)} .
\end{aligned}
$$

Syakir dkk. [8] memperkenalkan metode iterasi dengan mengubah perhitungan fungsi $f^{\prime \prime}\left(z_{n}\right)$ pada Persamaan (6) menjadi $f^{\prime \prime}\left(y_{n}\right)$ yang kembali dalam bentuk

$$
\begin{aligned}
y_{n} & =x_{n}-\frac{f\left(x_{n}\right)}{f^{\prime}\left(x_{n}\right)}, \\
z_{n} & =y_{n}-\left(1+\frac{2 f\left(y_{n}\right)}{f\left(x_{n}\right)}\right) \frac{f\left(y_{n}\right)}{f^{\prime}\left(x_{n}\right)}, \\
x_{n+1} & =z_{n}-\frac{2 f\left(z_{n}\right) f^{\prime}\left(z_{n}\right)}{2 f^{\prime}\left(z_{n}\right)^{2}-f\left(z_{n}\right) f^{\prime \prime}\left(y_{n}\right)} .
\end{aligned}
$$

Fungsi turunan kedua $f^{\prime \prime}\left(y_{n}\right)$ pada bagian ketiga Persamaan (7) diaproksimasi menggunakan polinomial yang diperoleh dengan menggunakan ekspansi Taylor seperti yang dilakukan oleh Noor dkk. [9], yaitu

$$
f^{\prime \prime}\left(y_{n}\right) \approx \frac{2}{y_{n}-x_{n}}\left(2 f^{\prime}\left(y_{n}\right)+f^{\prime}\left(x_{n}\right)-3 \frac{f\left(y_{n}\right)-f\left(x_{n}\right)}{y_{n}-x_{n}}\right) .
$$

Kemudian, $f^{\prime}\left(y_{n}\right)$ pada Persamaan (8) diaproksimasi dengan mempertimbangkan interpolasi Hermit orde dua seperti yang dilakukan oleh Muhaijir dan Aljarizi [7], dengan bentuk

$$
f^{\prime}\left(y_{n}\right) \approx 2\left(\frac{f\left(y_{n}\right)-f\left(x_{n}\right)}{y_{n}-x_{n}}\right)-f^{\prime}\left(x_{n}\right) .
$$

Jika Persamaan (9) disubstitusikan ke Persamaan (8), maka diperoleh

$$
f^{\prime \prime}\left(y_{n}\right) \approx \frac{2}{y_{n}-x_{n}}\left(\frac{f\left(y_{n}\right)-f\left(x_{n}\right)}{y_{n}-x_{n}}-f^{\prime}\left(x_{n}\right)\right)=T_{1} .
$$

Selanjutnya fungsi $f^{\prime}\left(z_{n}\right)$ pada langkah ketiga Persamaan (7) juga diaproksimasi dengan menggunakan interpolasi Lagrange orde tiga sebagaimana yang telah dilakukan oleh Wartono dan Rosela [2], yaitu

$$
\begin{aligned}
f^{\prime}\left(z_{n}\right) & \approx \frac{f\left(z_{n}\right)-f\left(x_{n}\right)}{z_{n}-x_{n}}+\frac{f\left(z_{n}\right)-f\left(y_{n}\right)}{z_{n}-y_{n}}-\frac{f\left(y_{n}\right)-f\left(x_{n}\right)}{y_{n}-x_{n}}, \\
& =f\left[z_{n}, x_{n}\right]+f\left[z_{n}, y_{n}\right]-f\left[y_{n}, x_{n}\right], \\
& =T_{2} .
\end{aligned}
$$


Persamaan (10) dan (11) disubstitusikan ke (7) sehingga diperoleh

$$
\begin{aligned}
y_{n} & =x_{n}-\frac{f\left(x_{n}\right)}{f^{\prime}\left(x_{n}\right)} \\
z_{n} & =y_{n}-\left(1+\frac{2 f\left(y_{n}\right)}{f\left(x_{n}\right)}\right) \frac{f\left(y_{n}\right)}{f^{\prime}\left(x_{n}\right)} \\
x_{n+1} & =z_{n}-\frac{2 f\left(z_{n}\right) T_{2}}{2 T_{2}^{2}-f\left(z_{n}\right) T_{1}}
\end{aligned}
$$

Persamaan (12) adalah metode iterasi baru tiga langkah yang merupakan kombinasi dari Persamaan (2), (3), dan (5) tanpa turunan kedua. Berikut ini ditunjukkan orde konvergensi metode iterasi Persamaan (12) yang disajikan pada Teorema 1.

Teorema 1 (Kekonvergenan Metode Iterasi) Misalkan $f: I \subset R \rightarrow R$ fungsi yang mempunyai turunan pada interval terbuka $I$. Selanjutnya asumsikan bahwa $\alpha$ adalah akar sederhana dari persamaan $f(x)=0$. Misalkan diberikan tebakan awal $x_{0}$ cukup dekat ke $\alpha$, maka metode iterasi Persamaan (12) mempunyai orde konvergensi tujuh dan memenuhi persamaan error:

$$
e_{n+1}=\left(2 c_{3}^{2} c_{2}^{2}-15 c^{4} c_{2}^{4}+25 c_{2}^{6}\right) e_{n}^{7}+O\left(e_{n}^{8}\right),
$$

dengan $c_{j}=\frac{f^{(j)}(\alpha)}{j ! f^{\prime}(\alpha)}, j \geq 1$ dan $e_{n}=x_{n}-\alpha$.

Bukti. Untuk menganalisis konvergensi Persamaan (12), misalkan $\alpha$ adalah akar sederhana dari Persamaan (1) dan $e_{n}$ adalah error pada iterasi ke- $n$, maka $e_{n}=x_{n}-\alpha$ dan $f(\alpha)=0$. Dengan menggunakan ekspansi Taylor untuk $f\left(x_{n}\right)$ di sekitar $x_{n}=\alpha$, sehingga diperoleh

$$
f\left(x_{n}\right)=f^{\prime}(\alpha)\left(e_{n}+c_{2} e_{n}{ }^{2}+c_{3} e_{n}{ }^{3}+\cdots+O\left(e_{n}^{8}\right)\right) .
$$

Selanjutnya, fungsi $f^{\prime}\left(x_{n}\right)$ diekspansi menggunakan deret Taylor di sekitar $\alpha$ diperoleh

$$
f^{\prime}\left(x_{n}\right)=f^{\prime}(\alpha)\left(1+2 c_{2} e_{n}+3 c_{3} e_{n}{ }^{2}+\cdots+O\left(e_{n}^{7}\right)\right) .
$$

Jika Persamaan (14) dibagi dengan Persamaan (15) maka diperoleh

$$
\frac{f\left(x_{n}\right)}{f^{\prime}\left(x_{n}\right)}=e_{n}-c_{2} e_{n}^{2}+2\left(c_{2}^{2}-c_{3}\right) e_{n}^{3}+\cdots+O\left(e_{n}^{8}\right) .
$$

Persamaan (16) disubstitusikan ke langkah pertama Persamaan (12) dan $x_{n}=\alpha+e_{n}$ diperoleh

$$
y_{n}=\alpha+c_{2} e_{n}^{2}+2\left(c_{3}-c_{2}^{2}\right) e_{n}^{3}+\cdots+O\left(e_{n}^{8}\right) .
$$

Menggunakan Persamaan (17) dan menerapkan ekspansi deret Taylor dari $y$ dengan $y=\alpha$, maka $y$ dievaluasi di $y=y_{n}$. Setelah dilakukan penyederhanaan diperoleh

$$
f\left(y_{n}\right)=f^{\prime}(\alpha)\left(c_{2} e_{n}^{2}+2\left(c_{3}-c_{2}^{2}\right) e_{n}^{3}+\cdots+O\left(e_{n}^{8}\right)\right) .
$$




\section{T. Adawiyah, et.al}

Berdasarkan Persamaan (18) dan (14) dengan melakukan perhitungan untuk $\frac{2 f\left(y_{n}\right)}{f\left(x_{n}\right)}$ setelah dilakukan penyederhanaan, diperoleh

$$
\frac{2 f\left(y_{n}\right)}{f\left(x_{n}\right)}=2 c_{2} e_{n}+\left(4 c_{3}-6 c_{2}^{2}\right) e_{n}^{2}+\cdots+O\left(e_{n}^{8}\right) .
$$

Selanjutnya, Persamaan (18) dibagi dengan Persamaan (15) diperoleh

$$
\frac{f\left(y_{n}\right)}{f^{\prime}\left(x_{n}\right)}=c_{2} e_{n}^{2}+\left(2 c_{3}-4 c_{2}^{2}\right) e_{n}^{3}+\cdots+O\left(e_{n}^{8}\right) .
$$

Persamaan (17), (19) dan (20) disubstitusikan ke langkah kedua Persamaan (12) menghasilkan

$$
z_{n}=\alpha+\left(5 c_{2}^{3}-c_{2} c_{3}\right) e_{n}^{4}+\cdots+O\left(e_{n}^{8}\right)
$$

Menggunakan Persamaan (21) dan menerapkan ekspansi deret Taylor dari $f(z)$ dengan $z=z_{n}$, maka $f(z)$ dievaluasi di $z=z_{n}$ setelah dilakukan penyederhanaan diperoleh

$$
f\left(z_{n}\right)=f^{\prime}(\alpha)\left(\left(5 c_{2}^{3}-c_{2} c_{3}\right) e_{n}^{4}+\cdots+O\left(e_{n}^{8}\right)\right) .
$$

Selanjutnya, $T_{1}$ pada persaman (10) dilakukan perhitungan dengan menyubstitusikan (14) dan (18) ke (10) diperoleh

$$
T_{1}=-\frac{2 c_{1}}{e_{n}}-4 c_{2}+\left(-6 c_{3}-2 c_{2}^{2}\right) e_{n}+\cdots+O\left(e_{n}^{8}\right) .
$$

Perhitungan $T_{2}$ pada Persamaan (11) dilakukan dengan menyubstitusikan Persamaan (14), (18), dan (22) ke Persamaan (11) menghasilkan

$$
T_{2}=c_{1}-c_{2} c_{3} e_{n}^{3}+\left(10 c_{2}^{4}-2 c_{3}^{3}-c_{2} c_{4}\right) e_{n}^{4}+\cdots+O\left(e_{n}^{8}\right) .
$$

Berdasarkan Persamaan (22) dan (24) untuk perhitungan $2 f\left(z_{n}\right) T_{2}$ setelah dilakukan penyederhanaan diperoleh

$$
2 f\left(z_{n}\right) T_{2}=\left(10 c_{2}^{3}-2 c_{2} c_{3}\right) e_{n}^{4}+\cdots+O\left(e_{n}^{8}\right) .
$$

Perhitungan $2 T_{2}^{2}-f\left(z_{n}\right) T_{1}$ dari Persamaan (22), (23), dan (24) menghasilkan

$$
2 T_{2}^{2}-f\left(z_{n}\right) T_{1}=-2 c_{1}^{2}+\left(2 c_{2} c_{3}+10 c_{2}^{3}\right) e_{n}^{3}+\cdots+O\left(e_{n}^{8}\right) .
$$

Selanjutnya, Persamaan (25) dan (26) disubstitusikan ke Persamaan (12) langkah ketiga, dan setelah dilakukan penyederhanaan diperoleh

$$
x_{n+1}=\alpha+\left(2 c_{3}^{2} c_{2}^{2}-15 c^{4} c_{2}^{4}+25 c_{2}^{6}\right) e_{n}^{7}+O\left(e_{n}^{8}\right) .
$$

Karena, $e_{n+1}=x_{n+1}-\alpha$ sehingga

$$
e_{n+1}=\left(2 c_{3}^{2} c_{2}^{2}-15 c^{4} c_{2}^{4}+25 c_{2}^{6}\right) e_{n}^{7}+O\left(e_{n}^{8}\right) .
$$


Berdasarkan definisi orde konvergensi [11] diperoleh metode iterasi tiga langkah kombinasi Persamaan (2), (3), dan (5) memiliki orde konvergensi tujuh, maka Teorema 1 terbukti.

Metode iterasi tiga langkah memiliki kekonvergenan orde tujuh dengan empat evaluasi fungsi $f\left(x_{n}\right), f\left(y_{n}\right), f\left(z_{n}\right)$, dan $f^{\prime}\left(x_{n}\right)$. Berdasarkan definisi indeks efisiensi [13], diperoleh indeks efisiensi sebesar $7^{1 / 4} \approx 1,6265$.

Selanjutnya, simulasi numerik dilakukan untuk membandingkan beberapa metode dengan metode iterasi tiga langkah. Perbandingan ini dilakukan pada persamaan nonlinear sebagai berikut

$$
\begin{array}{ll}
f_{1}(x)=(x-1)^{3}-1, & \alpha=2,0000000000 \\
f_{2}(x)=x e^{-x}-0,1, & \alpha=0,1118325591 \\
f_{3}(x)=\cos (x)-x, & \alpha=0,7390851332 \\
f_{4}(x)=x^{3}-10, & \alpha=2,5144346900 \\
f_{5}(x)=x^{3}+4 x^{2}-10, & \alpha=1,3652300134
\end{array}
$$

Solusi numerik dari ke lima persamaan nonlinear di atas, dilakukan dengan dua buah tebakan awal $x_{0}$ yang berbeda. Hal ini diperlukan karena tebakan awal berpengaruh terhadap keberhasilan dalam menghampiri akar dan juga terhadap jumlah iterasi yang dihasilkan. Perbandingan dilakukan dengan beberapa metode yaitu metode Newton $(\mathrm{MN})$, metode Abbasbandy (MA), metode Halley (MH), metode Arif-Muhaijir (MAM), dan metode Wartono-Rosela (MWR). Hasil komputasi dari perbandingan ke lima metode untuk empat fungsi di atas menggunakan program komputer Maple 13.

Tabel 1. Perbandingan komputasi beberapa metode untuk fungsi $f_{1}(x)=(x-1)^{3}-1$

\begin{tabular}{cccccc}
\hline$x_{0}$ & Metode & $n$ & COC & $\left|f\left(x_{n+1}\right)\right|$ & $\left|x_{n+1}-x_{n}\right|$ \\
\hline \multirow{4}{*}{1,5} & MN & 10 & 2,0000 & $9,19365 \mathrm{e}-180$ & $1,75059 \mathrm{e}-90$ \\
& MA & 9 & 3,0000 & $1,98212 \mathrm{e}-168$ & $1,25615 \mathrm{e}-56$ \\
& MH & 6 & 3,0000 & $5,35493 \mathrm{e}-214$ & $6,44527 \mathrm{e}-72$ \\
& MAM & 21 & 6,0000 & $5,54916 \mathrm{e}-212$ & $3,20360 \mathrm{e}-36$ \\
& MWR & 3 & 7,0000 & $7,45358 \mathrm{e}-177$ & $1,13381 \mathrm{e}-25$ \\
MIB & 8 & 7,0000 & $8,55042 \mathrm{e}-518$ & $7,55847 \mathrm{e}-75$ \\
\hline \multirow{5}{*}{2,5} & MN & 8 & 2,0000 & $8,43306 \mathrm{e}-112$ & $1,67661 \mathrm{e}-56$ \\
& MA & 5 & 3,0000 & $8,98123 \mathrm{e}-152$ & $4,47829 \mathrm{e}-51$ \\
& MH & 5 & 3,0000 & $5,90953 \mathrm{e}-121$ & $6,66051 \mathrm{e}-41$ \\
& MAM & 4 & 6,0000 & $1,13684 \mathrm{e}-368$ & $2,45971 \mathrm{e}-62$ \\
& MWR & 3 & 7,0000 & $2,95989 \mathrm{e}-328$ & $2,66572 \mathrm{e}-47$ \\
& MIB & 4 & 7,0000 & $4,08453 \mathrm{e}-672$ & $6,80141 \mathrm{e}-97$ \\
\hline
\end{tabular}


Tabel 2. Perbandingan komputasi beberapa metode untuk fungsi $f_{2}(x)=x e^{-x}-0,1$

\begin{tabular}{cccccc}
\hline$x_{0}$ & Metode & $n$ & COC & $\left|f\left(x_{n+1}\right)\right|$ & $\left|x_{n+1}-x_{n}\right|$ \\
\hline \multirow{4}{*}{$-0,1$} & MN & 8 & 2,0000 & $1,81145 \mathrm{e}-179$ & $4,63225 \mathrm{e}-90$ \\
& MA & 5 & 3,0000 & $9,21714 \mathrm{e}-274$ & $1,28894 \mathrm{e}-91$ \\
& MH & 5 & 3,0000 & $3,29629 \mathrm{e}-201$ & $1,91836 \mathrm{e}-67$ \\
& MAM & 3 & 6,0000 & $7,99998 \mathrm{e}-111$ & $2,78487 \mathrm{e}-19$ \\
& MWR & 3 & 7,0000 & $2,91464 \mathrm{e}-273$ & $1,39331 \mathrm{e}-39$ \\
& MIB & 3 & 7,0000 & $1,42088 \mathrm{e}-178$ & $2,53840 \mathrm{e}-26$ \\
\hline \multirow{6}{*}{2,0} & MN & 8 & 2,0000 & $1,14861 \mathrm{e}-134$ & $7,21828 \mathrm{e}-67$ \\
& MA & 5 & 3,0000 & $2,74795 \mathrm{e}-128$ & $2,17005 \mathrm{e}-42$ \\
& MH & 6 & 3,0000 & $6,33669 \mathrm{e}-274$ & $5,38570 \mathrm{e}-91$ \\
& MAM & 4 & 6,0000 & $1,02099 \mathrm{e}-424$ & $5,63108 \mathrm{e}-71$ \\
& MWR & 3 & 7,0000 & $1,01740 \mathrm{e}-180$ & $9,53720 \mathrm{e}-26$ \\
& MIB & 3 & 7,0000 & $5,35359 \mathrm{e}-119$ & $3,34460 \mathrm{e}-17$ \\
\hline
\end{tabular}

Tabel 3. Perbandingan komputasi beberapa metode untuk fungsi $f_{3}(x)=\cos (x)-x$

\begin{tabular}{cccccc}
\hline$x_{0}$ & Metode & $n$ & COC & $\left|f\left(x_{n+1}\right)\right|$ & $\left|x_{n+1}-x_{n}\right|$ \\
\hline \multirow{4}{*}{2,0} & MN & 7 & 2,0000 & $1,17199 \mathrm{e}-191$ & $5,63158 \mathrm{e}-96$ \\
& MA & 5 & 3,0000 & $7,16544 \mathrm{e}-120$ & $3,99633 \mathrm{e}-40$ \\
& MH & 5 & 3,0000 & $6,29918 \mathrm{e}-106$ & $1,48113 \mathrm{e}-35$ \\
& MAM & 3 & 6,0000 & $5,81719 \mathrm{e}-161$ & $3,52915 \mathrm{e}-27$ \\
& MWR & 3 & 7,0000 & $8,01295 \mathrm{e}-346$ & $1,43675 \mathrm{e}-49$ \\
MIB & 3 & 7,0000 & $6,57862 \mathrm{e}-322$ & $2,54221 \mathrm{e}-46$ \\
\hline \multirow{6}{*}{$-0,6$} & MN & 9 & 2,0000 & $2,15929 \mathrm{e}-106$ & $2,41726 \mathrm{e}-53$ \\
& MA & $*$ & $*$ & $*$ & $*$ \\
& MH & 6 & 3,0000 & $5,33979 \mathrm{e}-167$ & $6,50640 \mathrm{e}-56$ \\
& MAM & $*$ & $*$ & $*$ & $*$ \\
& MWR & 4 & 7,0000 & $1,97318 \mathrm{e}-568$ & $2,27064 \mathrm{e}-81$ \\
& MIB & 8 & 7,0000 & $3,18760 \mathrm{e}-213$ & $8,54450 \mathrm{e}-31$ \\
\hline
\end{tabular}

Tabel 4. Perbandingan komputasi beberapa metode untuk fungsi $f_{4}(x)=x^{3}-10$

\begin{tabular}{cccccc}
\hline$x_{0}$ & Metode & $n$ & COC & $\left|f\left(x_{n+1}\right)\right|$ & $\left|x_{n+1}-x_{n}\right|$ \\
\hline \multirow{4}{*}{1,5} & MN & 8 & 2,0000 & $1,41188 \mathrm{e}-109$ & $1,47799 \mathrm{e}-55$ \\
& MA & 6 & 3,0000 & $1,62241 \mathrm{e}-228$ & $1,17504 \mathrm{e}-76$ \\
& MH & 5 & 3,0000 & $4,26756 \mathrm{e}-131$ & $2,77364 \mathrm{e}-44$ \\
& MAM & 4 & 6,0000 & $1,03223 \mathrm{e}-156$ & $7,65414 \mathrm{e}-27$ \\
& MWR & 3 & 7,0000 & $7,45358 \mathrm{e}-177$ & $1,13381 \mathrm{e}-25$ \\
& MIB & 4 & 7,0000 & $4,09799 \mathrm{e}-401$ & $5,46468 \mathrm{e}-58$ \\
\hline \multirow{4}{*}{2,6} & MN & 8 & 2,0000 & $2,04504 \mathrm{e}-189$ & $1,77879 \mathrm{e}-95$ \\
& MA & 5 & 3,0000 & $3,67310 \mathrm{e}-251$ & $3,32413 \mathrm{e}-84$ \\
& MH & 5 & 3,0000 & $7,22831 \mathrm{e}-198$ & $1,53463 \mathrm{e}-66$ \\
& MAM & 3 & 6,0000 & $7,65414 \mathrm{e}-270$ & $2,93246 \mathrm{e}-20$ \\
& MWR & 3 & 7,0000 & $6,89900 \mathrm{e}-296$ & $1,12136 \mathrm{e}-42$ \\
& MIB & 3 & 7,0000 & $1,29451 \mathrm{e}-190$ & $6,44061 \mathrm{e}-28$ \\
\hline
\end{tabular}


Modifikasi Varian Metode Abbasbandy dengan Orde Konvergensi Tujuh ...

Tabel 5. Perbandingan komputasi beberapa metode untuk fungsi $f_{5}(x)=x^{3}+4 x^{2}-10$

\begin{tabular}{cccccc}
\hline$x_{0}$ & Metode & $n$ & COC & $\left|f\left(x_{n+1}\right)\right|$ & $\left|x_{n+1}-x_{n}\right|$ \\
\hline \multirow{4}{*}{1,5} & MN & 7 & 2,0000 & $6,11007 \mathrm{e}-153$ & $2,74724 \mathrm{e}-77$ \\
& MA & 4 & 3,0000 & $2,15934 \mathrm{e}-157$ & $5,99939 \mathrm{e}-53$ \\
& MH & 4 & 3,0000 & $2,44576 \mathrm{e}-101$ & $2,01963 \mathrm{e}-34$ \\
& MAM & 3 & 6,0000 & $8,77170 \mathrm{e}-209$ & $1,48072 \mathrm{e}-35$ \\
& MWR & 3 & 7,0000 & $1,94082 \mathrm{e}-455$ & $1,72209 \mathrm{e}-65$ \\
& MIB & 3 & 7,0000 & $5,40767 \mathrm{e}-340$ & $2,72120 \mathrm{e}-49$ \\
\hline \multirow{6}{*}{2,0} & MN & 8 & 2,0000 & $6,11007 \mathrm{e}-153$ & $2,74724 \mathrm{e}-77$ \\
& MA & 5 & 3,0000 & $5,08214 \mathrm{e}-201$ & $1,71929 \mathrm{e}-67$ \\
& MH & 5 & 3,0000 & $6,67188 \mathrm{e}-158$ & $2,82196 \mathrm{e}-53$ \\
& MAM & 4 & 6,0000 & $1,38269 \mathrm{e}-543$ & $2,34466 \mathrm{e}-91$ \\
& MWR & 3 & 7,0000 & $7,48382 \mathrm{e}-263$ & $5,60223 \mathrm{e}-38$ \\
& MIB & 3 & 7,0000 & $2,30306 \mathrm{e}-145$ & $1,73358 \mathrm{e}-21$ \\
\hline
\end{tabular}

Berdasarkan Tabel 1-5, dapat disimpulkan bahwa jumlah iterasi metode iterasi baru lebih sedikit dibandingkan dengan metode iterasi lainnya dan dilihat dari metode yang memiliki orde konvergensi yang sama yaitu metode MWR memberikan jumlah iterasi yang hampir sama. Selain itu, Tabel 1-5 juga memberikan informasi bahwa nilai fungsi yang dihasilkan sebagai salah satu kriteria pemberhentian iterasi, MIB secara keseluruhan memiliki nilai fungsi yang lebih kecil dibandingkan metode $\mathrm{MN}, \mathrm{MA}$, dan $\mathrm{MH}$ dan nilai COC dari MIB menunjukkan angka tujuh, hal ini lebih menguatkan hasil orde konvergensi yang dihasilkan dari ekspansi deret Taylor.

\section{Kesimpulan}

Metode Iterasi Baru (MIB) yang didiskusikan memiliki orde konvergensi tujuh dengan melibatkan empat evaluasi fungsi yaitu $f\left(x_{n}\right), f\left(y_{n}\right), f\left(z_{n}\right)$, dan $f^{\prime}\left(x_{n}\right)$. Metode ini memiliki indeks efisiensi $7^{1 / 4} \approx 1,6265$ lebih besar nilainya jika dibandingan metode Newton $2^{1 / 2} \approx 1,4142$, metode Abbasbandy $3^{1 / 3} \approx 1,4422$ dan metode Halley $3^{1 / 3} \approx$ 1,4422. Hasil numerik juga menunjukkan bahwa metode baru lebih baik dibandingkan dengan metode lainnya.

\section{Referensi}

[1] K. E. Atkinson and W. Han, Elementary Numerical Analysis, 3rd ed. New York: John Wiley and Sons Inc, 1989.

[2] Wartono and R. Rasela, "Modifikasi Varian Metode Newton dengan Orde Konvergensi Tujuh," J. Sains Mat. dan Stat., vol. 2, no. 2, pp. 32-38, 2016.

[3] W. Nazeer, A. Naseem, S. M. Kang, and Y. C. Kwun, "Generalized Newton Raphson's method free from second derivative," J. Nonlinear Sci. Appl., vol. 9, no. 1, pp. 2823-2831, 2016.

[4] E. Halley, "A New Exact and Easy Method for Finding the Roots on Any Questions Generally without any Previous Reduction," Philos. Trans. R. Sociaty London, vol. 18, pp. 136-148, 1694.

[5] A. Melman, "Geometry and Convergence of Euler's and Halley's Method," SIAM Rev., vol. 39, no. 4, pp. 726 - 735, 1997. 
[6] S. Abbasbandy, "Improving Newton-Raphson Method for Solving Nonlinear Equations by Modified Adomian Decomposition Method," Appl. Math. Comput., vol. 145, pp. 887-893, 2003.

[7] M. N. Muhaijir and Aljarizi, "Metode Iterasi Tiga Langkah dengan Konvergensi Orde Enam untuk Menyelesaikan Persamaan Nonlinear," J. Sains Mat. dan Stat., vol. 4, no. 1, pp. 1-8, 2018.

[8] A. Syakir, M. Imran, and M. D. H. Gamal, "Combination of Newton-HalleyChebyshev Iterative Methods Without Second Derivatives," Int. J. Theor. Appl. Math., vol. 3, no. 3, pp. 106-109, 2017.

[9] M. A. Noor, W. A. Khan, K. I. Noor, and E. Al-said, "Higher-Order Iterative Methods Free from Second Derivative for Solving Nonlinear Equations," Int. J. Phys. Sci., vol. 6, no. 6, pp. 1887-1893, 2011.

[10] K. E. Atkinson, An Introduction to Numerical Analysis, 2nd ed. New York: John Wiley and Son Inc., 1989.

[11] L. Tornheim, "Convergence of Multipoint Iterative Methods," J. Assoc. Comput. Mach., vol. 11, no. 2, pp. 210-220, 1964.

[12] D. D. Wall, “The Order of an Iteration Formula," Math. Comput., vol. 10, no. 1, pp. 167-168, 1956.

[13] W. Gautschi, Numerical Analysis, 2nd ed. New York: Birkhauser, 2012. 